\title{
Modelling water utilization patterns in apple orchards with varying canopy sizes and different growth stages in semi-arid environments
}

\author{
Nompumelelo Thelma Mobe ${ }^{\mathrm{a}, \mathrm{c}, *}$, Sebinasi Dzikiti ${ }^{\mathrm{b}}$, Timothy Dube ${ }^{\mathrm{c}}$, Dominic Mazvimavi $^{\mathrm{c}}$, \\ Zanele Ntshidi ${ }^{\text {a,c }}$ \\ ${ }^{a}$ Council for Scientific and Industrial Research, Smart Places Cluster, P.O Box 3957 Meiring Naude, Pretoria, 0001, South Africa \\ ${ }^{\mathrm{b}}$ Department of Horticultural Science, Stellenbosch University, P. Bag X1, Matieland, 7602, South Africa \\ ${ }^{\mathrm{c}}$ Institute for Water Studies, Department of Earth Sciences, University of Western Cape, P. Bag X17, Bellville, 7535, South Africa
}

\section{A R T I C L E I N F O}

\section{Keywords:}

Malus domestica

ET partitioning

Soil evaporation

Stress factors

Transpiration

Water resources management

\begin{abstract}
A B S T R A C T
Accurate estimates of orchard evapotranspiration (ET) and its components are important for precise irrigation scheduling, irrigation system designs, and optimal on-farm water allocation particularly in water-limited environments. Direct measurements of ET remain costly, laborious and sometimes difficult to apply over heterogeneous surfaces such as crop fields. Therefore, accurate crop water-use models are required for on-farm precise water resources management. In this study, we adopted and improved the Priestley-Taylor Jet Propulsion Laboratory (PT-JPL) model developed by Fisher et al 2008 to estimate crop water use across different apple plants. Specifically, the model was developed to quantify the partitioning of apple orchard water use into beneficial (tree transpiration) and non-beneficial water use (orchard floor evaporation) as influenced by tree canopy cover. Data were collected in twelve orchards spread across key apple producing regions in the Western Cape Province of South Africa over three growing seasons (2014/15, 2015/16, 2016/17). Model ET estimates were tested against ET data measured; using the eddy covariance method and transpiration measured based on sap flow monitoring techniques. The results showed that the original Fisher PT-JPL model performed poorly in ET estimation across all the orchards under study. The model yielded lower $\mathrm{R}^{2}$, ranging from 0.02 to 0.64 and Nash-Sutcliffe Efficiency (NSE) from -10.93 to 0.20 . Thus, we subsequently improved the model by incorporating soil moisture and vapour pressure deficit stress factors and by introducing a variable Priestley and Taylor coefficient $(\alpha)$. The modified PT-JPL model demonstrated an improvement in ET estimates. The root mean square of error (RMSE) of the estimated daily ET varied from $\pm 0.60 \mathrm{~mm} / \mathrm{d}$ to $\pm 1.99 \mathrm{~mm} / \mathrm{d}$ whereas the mean absolute error (MAE) varied from $\pm 0.49 \mathrm{~mm} / \mathrm{d}$ to $\pm 1.91 \mathrm{~mm} / \mathrm{d}$, while the $\mathrm{R}^{2}$ varied from 0.54 to 0.75 in orchards with varying canopy cover. The findings of this work underscore the utility of the modified PT-JPL model for estimating ET and its components in apple orchards from planting until the trees reach full-bearing age.
\end{abstract}

\section{Introduction}

Evapotranspiration (ET) generally represents the greatest loss of water from irrigated orchards in semi-arid regions and it is sensitive to changes in the cover of vegetation (Wang and Wang, 2017). Accurate estimates of orchard ET and its components are important for precise irrigation scheduling, irrigation system designs, and optimal on-farm water allocation. This information is particularly important in countries like South Africa where the frequency and severity of droughts is increasing in the major fruit producing regions (Volschenk, 2017). In these regions, it is expected that irrigation demand will increase in the near future yet water resources face serious threats (Midgley and Lotze, 2011). There therefore, is a need to identify and adopt effective irrigation management strategies that increase the water productivity, i.e. producing more fruit per unit volume of water used (Gush et al., 2019).

In recent years, methods and tools needed to improve management of actual water use by crops in irrigated agriculture have significantly increased providing useful insights on plant water use patterns (Koech and Langat, 2018). These include:1) the soil water balance methods (Gong et al., 2007), 2) lysimetry (Mpelasoka et al., 2001), 3) eddy covariance (Ouyang et al., 2013), 4) Bowen ratio energy balance (Zanotelli et al., 2019), 5) scintillometry, 6) sap flow methods

\footnotetext{
* Corresponding author at: Council for Scientific and Industrial Research, Stellenbosch, South Africa.

E-mail address: 3764716@myuwc.ac.za (N.T. Mobe).
} 
(Fernández, 2017), (7) remote sensing energy balance (Odi-Lara et al., 2016), and 8) satellite based evapotranspiration (ET) estimates using vegetation indices (Liou and Kar, 2014). However, the drawback of these methods is that they are expensive and computationally complex. For example, they require unique technical expertise and a considerable dedication of time and effort (Elfarkh et al., 2020). Given the practical limitations of these methods, the development of simple but robust and operational models for estimating water use is required.

To date, a number of models were developed and are presently used to estimate actual water use in fruit trees. Examples include the Soil Water Balance (SWB) model (Annandale et al., 2003; Volschenk et al., 2003), the big leaf Penman-Monteith type model (e.g. Dragoni and Lakso, 2011; Rana et al., 2005), dual source Shuttleworth and Wallace type models (e.g. Ortega-Farias et al., 2012; Li et al., 2010; Allen et al., 1998 and Dzikiti et al., 2018a) and models using remote sensing data (Odi-Lara et al., 2016). Given the heterogeneity that characterises orchard environments comprising trees in rows, bare ground, cover crops, and at times the mulch, dual source models provide more accurate ET estimates. These models partition ET into transpiration (T) and substrate/orchard floor evaporation (Es) components (Kool et al., 2014; Dzikiti et al., 2017, 2018a). However, many of these models require parameters such as the aerodynamic and stomatal resistances, which are not easy to obtain, and they can be sources of uncertainty.

To address this, we modified the PT-JPL model developed by Fisher et al., 2008, which avoids the calculation of both the aerodynamic and surface resistances. The accuracy of this method depends mainly on the biophysical multipliers or stress factors that scale potential ET to actual ET, using a minimum amount of meteorological data and vegetation parameters (Aragon et al., 2018). The PT-JPL model has intensively been used for estimating ET worldwide and has been successfully applied over a wide range of biomes that included croplands, deciduous broadleaf forests, evergreen needle leaf forests, and grasslands, mixed forests, Savannas and open shrub-lands (Zhang et al., 2017; Shao et al., 2019; and Yang et al., 2019) but its application and performance in orchards remains undocumented. The results from these studies showed moderate to strong relationships between observed and actual ET estimated using the PT-JPL (García et al., 2013; Ding et al., 2013; Zhang et al., 2017; Moyano et al., 2018; Shao et al., 2019; Dzikiti et al., 2019; and Gomis-Cebolla et al., 2019). This information therefore indicated that this model can be useful where detailed meteorological data are not available.

The goal of this present work was to parameterize and evaluate the utility and the performance of the PT-JPL model in twelve apple orchards with varying canopy sizes ranging from young low canopy to mature high canopy cover orchards in the Western Cape Province of South Africa. To our knowledge, this model has not widely applied to crop fields and its performance in orchards of varying canopy cover characteristics remains unknown. The main objectives of this study were; (1) to apply the original PT-JPL model as published in apple orchards with varying fractional canopy cover and different cultivars, and (2) to re-parameterize and improve the PT-JPL model applied to row irrigated tree crops such as fruit orchards in semi-arid regions.

\section{Materials and methods}

\subsection{Study site and experimental orchards}

To evaluate and validate the performance of the PT-JPL model across orchards with varying attributes (canopy cover and cultivar), in-situ data were collected from 12 commercial apple (Malus domestica Borkh) orchards over three growing seasons 2014/15, 2015/16 and 2016/17. The orchards were situated in two prime apple-producing regions in the Western Cape Province of South Africa. The regions include the Koue Bokkeveld (KBV) plateau near the town of Ceres $\left(-33^{\circ} 22^{\prime} 8.00^{\prime \prime} \mathrm{S}, 19^{\circ}\right.$ $18^{\prime} 39.42^{\prime \prime} \mathrm{E}, 457 \mathrm{~m}$ asl) and the lower-lying Elgin/Grabouw/Vyeboom/ Villiersdorp (EGVV) near the town of Villiersdorp ( $-33^{\circ} 58^{\prime} 59.99^{\prime \prime} \mathrm{S}, 19^{\circ}$ $16^{\prime} 60.00^{\prime \prime} \mathrm{E}, 336 \mathrm{~m}$ asl).

During the first and second growing seasons, data were collected in eight orchards, which included four mature orchards ranging between 9-29 years (with effective canopy cover varying from 45 to $52 \%$ ) and four young non-bearing orchards aged three to four years (with low canopy cover of between $14 \%$ and $26 \%$ ). Mature high canopy cover orchards were planted to the Golden Delicious and Cripps Pink cultivars, whereas young low canopy cover orchards were planted to Golden Delicious Reinders $₫$ and Cripps Red/Rosy Glow apple cultivars. Data were collected in four orchards (comprising two mature high and two young low canopy cover orchards) in KBV during the 2014/15 season and a further four orchards in EGVV during the 2015/16 growing season. The two mature high canopy Golden Delicious (22 yrs old) and Cripps Pink $(\sim 9$ yrs old) orchards studied in KBV were located next to each other, each planted on 6 ha in size. Tree spacing in both mature high canopy cover orchards were $4 \mathrm{~m} \times 1.5 \mathrm{~m}$ giving a plant density of 1667 trees per hectare. The young low canopy cover orchard on the other hand comprised a three year old Golden Delicious Reinders ${ }^{\circledR}$ cultivar. The orchard was about 3.17 ha in size and tree were spaced at $4 \mathrm{~m} \times 1.5 \mathrm{~m}$ (i. e. 1667 trees/ha). The second low canopy cover Rosy Glow orchard was about 4 yrs old and 6.3 ha in size. Tree spacing was $3.5 \mathrm{~m} \times 1.25 \mathrm{~m}$ giving a substantially higher plant density of 2285 trees per hectare.

In EGVV, the mature high canopy cover Golden Delicious orchard was 29 yrs old and the trees were planted on gentle sloping terrain in an east-west direction. Orchard size was approximately 5.5 ha and trees were planted with $4 \mathrm{~m} \times 2 \mathrm{~m}$ spacing. The mature high cover Cripps Pink orchard was about 5.2 ha in size and it was planted in 2004 ( $\sim 12$ yrs old) on an east facing slope. Tree spacing was about $4 \mathrm{~m} \times 1.5 \mathrm{~m}$. The young low canopy cover Golden Delicious Reinders ${ }^{\circledR}$ orchard was planted in 2011 ( $\sim 4$ yrs old) and the orchard was 6.0 ha in size and tree spacing was $4 \mathrm{~m} \times 2 \mathrm{~m}$. The non-bearing Cripps Red orchard on the other hand was 3 yrs old and it was more than 5.0 ha in size. Tree spacing was $3.5 \mathrm{~m} \times 1.25 \mathrm{~m}$ (i.e. 2285 trees per ha).

In the 2016/17 season, measurements were taken in two orchards in each production region with medium fractional canopy cover ranging from 0.26 to 0.37 planted to the same cultivars. A detailed description of the study sites is given by Mobe et al. (2020a, b) and Dzikiti et al. (2018a, b). All the orchards were planted on deep sandy to sandy loam soils except for the mature high canopy cover Cripps Pink, young low canopy cover Golden Delicious Reinders ${ }^{\circledR}$ and the medium canopy cover Cripps Pink in the EGVV region. Soil texture in these orchards was predominantly dark red clay loam soils of the Kroonstad soil form (Ochric Planosol) according to the Soil Classification Working Group (1991).

\subsection{Transpiration, evapotranspiration and weather data}

Transpiration in the medium and mature high canopy cover orchards were monitored using the heat ratio method (HRM) for measuring sap flow rates in plants described by (Burgess et al., 2001). Three to six trees with different stem sizes in each orchard were instrumented from the beginning of October to the end of May in each of the seasons. In young low canopy cover orchards, sap flow was measured using commercially available Granier probes (Model: TDP 10, Dynamax Inc., Houston USA) (Granier, 1987). Further details on the installation of HRM and Granier probe equipment utilised are provided by Mobe et al. (2020a, b). Actual evapotranspiration (ET) was measured using an open-path eddy covariance (EC) system that was deployed in each orchard during specific window periods to measure the latent and sensible heat fluxes. Details regarding the instrumentation, data processing and deployment periods can be found in Mobe et al. (2020a). Orchard microclimate was measured using automatic weather stations installed in an open space with uniform grass close to each orchard. 


\subsection{Soil water content}

In each orchard, detailed seasonal dynamics of the soil water content was monitored continuously at different depths in the root zone and beyond ( $\sim 30$ to $110 \mathrm{~cm}$ ). Three to 30-time-domain reflectometer probes (Model: CS616, Campbell Sci. Inc., Logan, UT, USA) connected to dataloggers (Model: CR1000, Campbell Scientific, Inc., Logan UT, USA) were used to measure the soil water content and all the outputs were sampled every $60 \mathrm{~min}$.

\subsection{Satellite data}

Since PT-JPL model requires the normalized difference vegetation index (NDVI) and fractional vegetation cover as input parameters, Landsat and Sentinel images with less than $10 \%$ cloud cover were downloaded from the USGS Earth Explorer data portal (http://earth explorer.usgs.gov) website for the three growing seasons. Landsat 8 images were only used for one growing season $(2014 / 15)$ in the KBV region since Sentinel 2 was launched in June 2015. The images were atmospherically corrected using the Dark Object Subtraction (DOS1) model under Semi-Automated Classification (SCP) embedded in Quantum GIS 3.4.10 software. All image bands were converted from digital number values to reflectance. The NDVI values can range from -1.0-1.0, where NDVI close to 1 indicates dense green vegetation cover and a value close to 0 no vegetation, possibly urban areas and negative values mainly result from water.

The NDVI was calculated as:

$N D V I=\frac{N I R-R E D}{N I R+R E D}$

where NIR and RED are the reflectance of near infrared and red wavebands, respectively. A description of the spectral bands that make up Sentinel 2 and Landsat 8 are shown in Table 1. For Sentinel, Band 8 and band 4 were used whereas for Landsat, bands 5 and 4 were used.

\subsection{Modelling water use of apple orchards with the PT-JPL model}

The daily ET and its components were modelled using the PT-JPL model. The accuracy of this model mainly depends on accurate determination of eco-physiological constraint functions to downscale potential ET to actual evapotranspiration. A detailed description of the original PT-JPL model is provided in Fisher et al. (2008). Here the focus is on changes that improved the performance of the model in apple orchards with varying canopy cover. The latent heat flux $\left(\lambda E\right.$, in $\left.\mathrm{W} \mathrm{m}^{-2}\right)$ was calculated as:

$\lambda E=\lambda E_{c}+\lambda E_{s}$

where $\lambda E c\left(\mathrm{~W} \mathrm{~m}^{-2}\right)$ is the energy equivalent of canopy transpiration and $\lambda E s\left(\mathrm{~W} \mathrm{~m}^{-2}\right)$ is the energy for soil evaporation. For this particular study, the evaporation from a wet canopy surface was not considered, as this did not improve the model given that we were dealing with microsprinkler irrigated crops. Using the original model and the suggested eco-physiological stress factors and parameters as published by Fisher et al. (2008) on apple orchards led to significant poor model performance for ET estimation and its constituent components ( $T$ and $E_{s}$ ) for orchards of all age groups as will be discussed in detail in the results section. It is known that water use from apple orchards is highly sensitive to soil water deficit and the vapour pressure deficit of the air (VPD) (Dzikiti et al., 2018a; Lo Bianco, 2019). Therefore, the model was subsequently improved by introducing two stress factors; one for soil moisture $\left(f_{S M}\right)$ and the other for vapour pressure deficit of the air $\left(f_{V P D}\right)$. We also replaced the general $\mathrm{P} \& \mathrm{~T}$ coefficient often take as $\sim 1.26$ by adopting a variable coefficient as described by Tanner and Jury (1976). This approach partitions the $\mathrm{P} \& \mathrm{~T}$ coefficient into the soil evaporation $\left(\alpha_{s}\right)$ and canopy transpiration coefficients $\left(\alpha_{c}\right)$, respectively. A number of studies have shown that the general P \& T coefficient is not constant over the entire growing season. It however, varies greatly with crop type, soil moisture availability and climatic conditions (Lei and Yang, 2010; Pereira et al., 2007). Soil evaporation $\left(\alpha_{s}\right)$ and canopy transpiration $\left(\alpha_{c}\right)$ coefficients were then calculated according to Agam et al. (2010) as:

$\boldsymbol{\alpha}_{s}=\left\{\begin{array}{l}1 \text { for } \tau \leq \tau_{0} \\ \alpha-\frac{(\alpha-1)(1-\tau)}{1-\tau_{0}} \text { for } \tau>\tau_{0}\end{array}\right.$
$\alpha_{c}=\frac{\left(\alpha-\alpha_{s} \tau\right)}{(1-\tau)}$

where $\alpha$ is the P \& T coefficient, taken as $1.26, \tau_{0}$ is a critical value of $\tau$ at which canopy cover is sufficient, which ranges between $0.20-0.50$ and $\tau$ is the fraction of net radiation transmission reaching the soil surface, calculated based on the Beer-Lambert's law as:

$\tau=\exp \left(-k_{R n} \times L A I\right)$

where $k_{R n}$ is the extinction coefficient for net radiation, which was taken as a constant with a value of 0.6 (Li et al., 2010) and LAI is the leaf area index which was calculated as:

$L A I=\left(-\ln \left(1-f_{I P A R}\right) / k_{P A R}\right)$

where $k_{P A R}$ is the extinction coefficient for photosynthetically active radiation with a value of 0.5 and $f_{I P A R}$ is the fraction of the photosynthetically active radiation (IPAR) intercepted by the canopy calculated as: $f_{I P A R}=N D V I-0.05$ (Ershadi et al., 2014).

The canopy transpiration was estimated, using four physiological constraints/ stress factors considered to regulate potential transpiration.

$\lambda E_{c}=f_{g} f_{T} f_{S M} f_{V P D} \alpha_{C} \frac{\Delta}{\Delta+\gamma}\left(R_{n}-R_{n s}\right)$

where $f_{g}$ is the green canopy fraction, $f_{T}$ is the plant temperature constraint, $f_{S M}$ is the soil moisture constraint, $f_{V P D}$ is the vapour pressure deficit (VPD) constraint, $\alpha_{c}$ is the modified canopy transpiration $\mathrm{P} \& \mathrm{~T}$ coefficient, $\Delta$ is the slope of the saturated vapour pressure versus air temperature curve $\left(\mathrm{kPa}{ }^{\circ} \mathrm{C}^{-1}\right), \gamma$ is the psychrometric constant $(\mathrm{kPa}$ ${ }^{\circ} \mathrm{C}^{-1}$ ), $R_{n}$ is the net radiation ( $\mathrm{W} \mathrm{m}^{-2}$ ) incident at the top of the canopies

Table 1

Corresponding Landsat- 8 and Sentinel-2 bands and characteristics considered in this study.

\begin{tabular}{|c|c|c|c|c|c|}
\hline \multicolumn{3}{|l|}{ Landsat 8} & \multicolumn{3}{|l|}{ Sentinel 2} \\
\hline Band & Wavelength $(\mu \mathrm{m})$ & Resolution (m) & Band & Wavelength $(\mu \mathrm{m})$ & Resolution (m) \\
\hline Band 2 - Blue & $0.45-0.51$ & 30 & Band 2 - Blue & $0.46-0.52$ & 10 \\
\hline Band 3 - Green & $0.53-0.59$ & 30 & Band 3 - Green & $0.54-0.58$ & 10 \\
\hline Band 4 - Red & $0.64-0.67$ & 30 & Band 4 - Red & $0.65-0.68$ & 10 \\
\hline \multirow[t]{2}{*}{ Band 5 - NIR } & $0.85-0.88$ & 30 & Band 8 - NIR & $0.79-0.90$ & 10 \\
\hline & & & Band $8 \mathrm{~A}$ - vegetation red edge & $0.85-0.87$ & 20 \\
\hline Band 6 - SWIR 1 & $1.57-1.65$ & 30 & Band 11 - SWIR 1 & $1.57-1.66$ & 20 \\
\hline Band 7 - SWIR 2 & $2.11-2.29$ & 30 & Band 12 - SWIR 2 & $2.10-2.28$ & 20 \\
\hline
\end{tabular}

NIR $=$ Near infrared and SWIR = Shortwave infrared. 
and $R_{n s}\left(\mathrm{~W} \mathrm{~m}{ }^{-2}\right)$ is the net radiation that reaches the soil surface which was calculated following Beer's law:

$R n_{s}=\left(R_{n} \exp \left(-k_{R n} L A I\right)\right)$

The soil evaporation component was then calculated as:

$\lambda E_{s}=f_{S M} \alpha_{s} \frac{\Delta}{\Delta+\gamma}\left(R_{n s}-G\right)$

where $\alpha_{s}$ is the modified soil evaporation P \& T coefficient and $G$ is the soil heat flux $\left(\mathrm{W} \mathrm{m}^{-2}\right)$. The eco-physiological constraint functions which are used as a proxy for plant and water stress are given by the following (Ershadi et al., 2014):

$f_{g}=\frac{f_{A P A R}}{f_{I P A R}}$

$f_{T}=\exp \left(-\left(\frac{T^{\max }-T_{o p t}}{T_{o p t}}\right)^{2}\right)$

$f_{S M}=\left(\frac{S W C-S W C_{\min }}{S W C_{\max }-S W C_{\min }}\right)^{\beta}$

$f_{V P D}=\exp \left(-k_{v p d} \times V P D\right)$

where $f_{A P A R}$ is the fraction of the photosynthetically active radiation absorbed PAR calculated as: $f_{A P A R}=m_{1} \times N D V I+b_{1}$ where $m_{1}, b_{1}, \beta$ and $k_{v p d}$ are parameters obtained by model optimization (Table 2), $T_{\max }$ is the daily maximum temperature at which stomata close (in ${ }^{\circ} \mathrm{C}$ ), $T_{\text {opt }}$ is the optimum temperature for the growth of apple trees (in ${ }^{\circ} \mathrm{C}$ ), $S W C$ is the average daily volumetric soil water content $\left(\mathrm{cm}^{3} / \mathrm{cm}^{3}\right)$ measured using the CS616 soil moisture probes, $S W C_{\min }$ is the volumetric soil water content at the permanent wilting point and $S W C_{\max }$ is the volumetric soil water content at the field capacity.

\subsection{Assessment of model performance}

Daily values of measured and estimated actual ET, and its component (T) were compared using the linear regression analysis. Root mean square error (RMSE), mean absolute error (MAE), and Nash-Sutcliffe efficiency (NSE) were used to evaluate the model's performance as:

Table 2

Model parameters used in estimating Priestley-Taylor Jet Propulsion Laboratory (PT-JPL) daily biophysical constraints, plant variables and energy variables applied to high, medium and low canopy cover orchards.

\begin{tabular}{|c|c|c|c|}
\hline Parameter & Description & Values & References \\
\hline$\alpha P T$ & Priestly and Taylor coefficient & 1.26 & $\begin{array}{l}\text { (Priestley and } \\
\text { Taylor, 1972) }\end{array}$ \\
\hline$\beta$ & & 1 & $\begin{array}{l}\text { Fisher et al., } \\
2008\end{array}$ \\
\hline$b 1$ & & $1.2 *-0.04$ & $\begin{array}{l}\text { Fisher et al., } \\
2008\end{array}$ \\
\hline$b 2$ & & -0.05 & $\begin{array}{l}\text { Fisher et al., } \\
2008\end{array}$ \\
\hline$m 1$ & & $1.2 * 1.136$ & $\begin{array}{l}\text { Fisher et al., } \\
2008\end{array}$ \\
\hline$m 2$ & & 1.0 & $\begin{array}{l}\text { Fisher et al., } \\
2008\end{array}$ \\
\hline$\tau_{0}$ & $\begin{array}{l}\text { Critical value of } \tau \text { at which canopy } \\
\text { cover is sufficient }\end{array}$ & $0.20-0.50$ & Agam et al., 2010 \\
\hline$k_{v p d}$ & & 0.20 & This study \\
\hline$k_{P A R}$ & $\begin{array}{l}\text { Extinction coefficient for } \\
\text { photosynthetically active radiation }\end{array}$ & 0.50 & $\begin{array}{l}\text { Fisher et al., } \\
2008\end{array}$ \\
\hline$k_{R n}$ & $\begin{array}{l}\text { Extinction coefficient for net } \\
\text { radiation }\end{array}$ & 0.60 & Li et al., 2010 \\
\hline$T_{\text {opt }}$ & $\begin{array}{l}\text { Optimum temperature for plant } \\
\text { growth }\end{array}$ & $25^{\circ} \mathrm{C}$ & $\begin{array}{l}\text { Fisher et al., } \\
2008\end{array}$ \\
\hline
\end{tabular}

$R M S E=\left[\frac{1}{N} \sum_{i=1}^{N}\left(Y_{i}^{o b s}-Y_{i}^{s i m}\right)^{2}\right]^{0.5}$

$M A E=\frac{1}{N} \sum_{i=1}^{N}\left|Y_{i}^{o b s}-Y_{i}^{s i m}\right|$

$N S E=1-\left[\frac{\sum_{i=1}^{n}\left(Y_{i}^{\text {obs }}-Y_{i}^{\text {sim }}\right)^{2}}{\sum_{i=1}^{n}\left(Y_{i}^{\text {obs }}-Y_{i}^{\text {sim }}\right)^{2}}\right]$

where $N$ is the total number of observations, the subscript $i$ denoted the ith observation, $Y^{\text {obs }}$ and $Y^{\text {sim }}$ superscripts refers to the measured and modelled values and $Y^{\text {mean }}$ are the means of the model-based and measured values, respectively.

\section{Results and discussion}

The normalised difference vegetation index has been used widely to study the relation between spectral variability and the changes in vegetation growth rate. It is also used as a proxy for vegetation greenness as well as to detect vegetation changes. The time series of the monthly NDVI values in apple orchards with varying canopy cover are depicted in Fig. 1a-c. The mature high canopy orchards had the highest NDVI values, followed by medium canopy cover orchards and young low canopy cover orchards had the lowest values. As shown in Fig. 1 a, the highest NDVI values in mature orchards were found when the trees
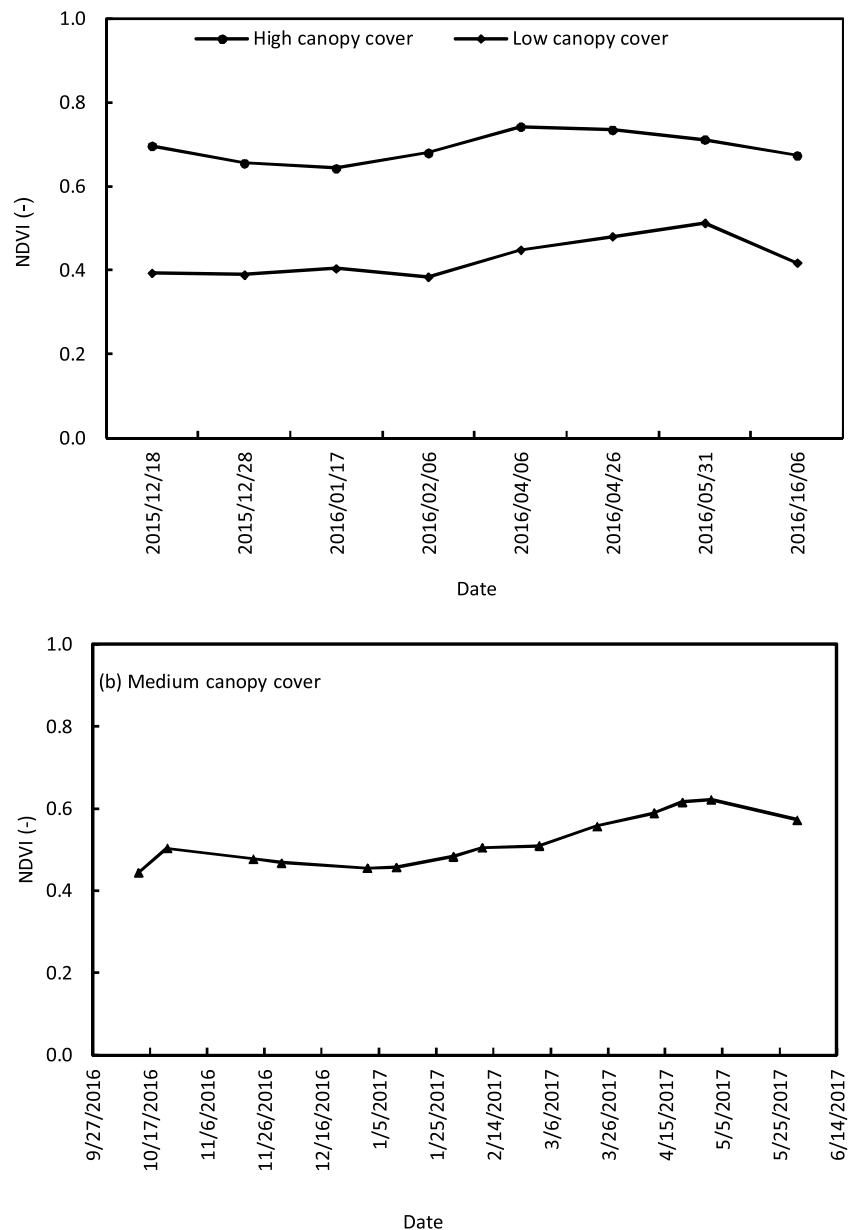

Fig. 1. Time series of normalised difference vegetation index (NDVI) values of apple orchards with a) high and low, b) medium canopy covers. 
reached full canopy and the values ranged between 0.64 and 0.74 with the average orchard LAI of $\sim 3.4$. The young low canopy cover orchards had the lowest NDVI values when compared to the medium and mature orchards, with values ranging from 0.38 to 0.51 . It can be seen from the study, that the denser the canopy cover, the higher the values of NDVI as expected.

\subsection{Measured $v s$ original PT-JPL modelled ET}

Fig. 2 (a-c) shows the correlations between the flux tower and modelled ET performance for selected window periods when actual ET data was collected, and Table 3 highlights the model performance. The regression analysis showed a poor linear relationship between simulated and measured daily ET for all the orchards with high, medium and low canopy cover (Fig. 2). The coefficient of determination $\left(\mathrm{R}^{2}\right)$ ranged between 0.21 and 0.35 , NSE was $-1.55,-1.19$ and 0.20 for mature high, medium and young low canopy covers, respectively (Table 3 ). The NSE values were significantly less than zero and not closer to one for all the orchards suggesting poor performance of the model. Similar results were observed for the remaining four orchards that had sufficient ET data points.

Fig. 3a \& b, presents the variation of the modified canopy transpiration and soil evaporation $\mathrm{P} \& \mathrm{~T}$ coefficient for orchards with varying age groups. It is evident from results that the modified $\mathrm{P} \& \mathrm{~T}$ coefficient differed greatly from the general value of 1.26 . The ranges of the modified canopy transpiration P \& T coefficient values were 1.33-1.39,
$1.41-1.58$, and $1.48-1.58$ for the mature high canopy, medium canopy, and young low canopy cover orchards, respectively. For the soil evaporation, the P \& T coefficient was highest under the young low canopy cover orchards, followed by the medium and then the mature high canopy cover orchards. The magnitude of both the canopy transpiration and soil evaporation $\mathrm{P} \& \mathrm{~T}$ coefficients were mainly driven by the direct effect of LAI. Therefore, it can be deduced from the study that the smaller the fractional cover (LAI), the higher the soil evaporation and canopy transpiration P \& T coefficient.

Although a number of studies have showed that the constant Priestley and Taylor coefficient of 1.26 gives accurate ET estimates on some vegetation types (Pereira, 2004; Utset et al., 2004), the present study showed that a variable coefficient was required for orchards with different canopy cover. This is consistent with the findings from other researchers (e.g. Pereira et al., 2007; Qiu et al., 2019; Ding et al., 2013; Agam et al., 2010) that indicated that $(\alpha)$ had a large variation over the whole growing season, especially for daily time scales. The main reported factors affecting $(\alpha)$ include mulching method, green canopy fraction, air temperature, soil moisture availability, relative humidity, etc. (Ding et al., 2013; Yao et al., 2013; Ershadi et al., 2014; Ai and Yang, 2016). In this study the $P \& T$ coefficient was not constant, it varied with the size of canopy cover for apple orchards, with $\left(\alpha_{s}\right)$ and $\left(\alpha_{c}\right)$ values relatively larger in young open canopy orchards (LAI $\sim 1.0$ ) as compared to mature high canopy orchards (LAI $\sim 3.0$ ). These results suggest that the modified PT-JPL model could accurately estimate evapotranspiration of irrigated apple orchard from planting until they

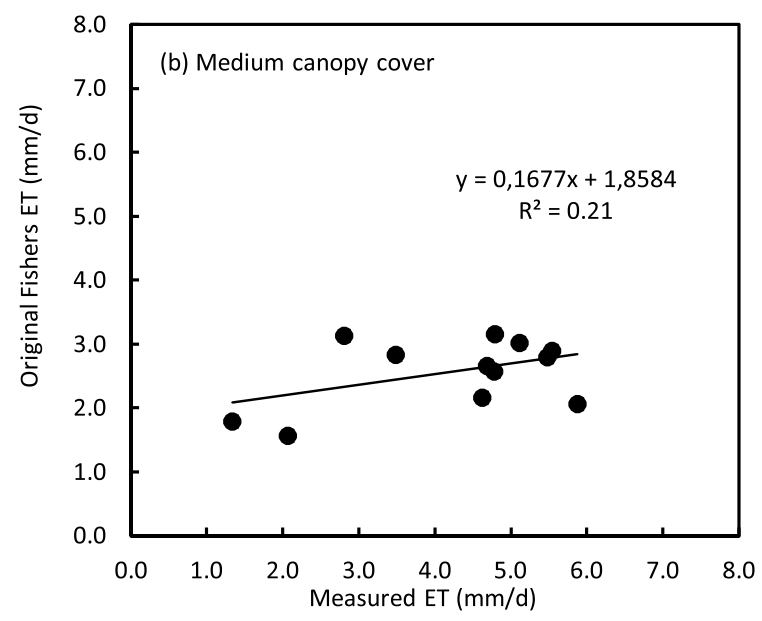

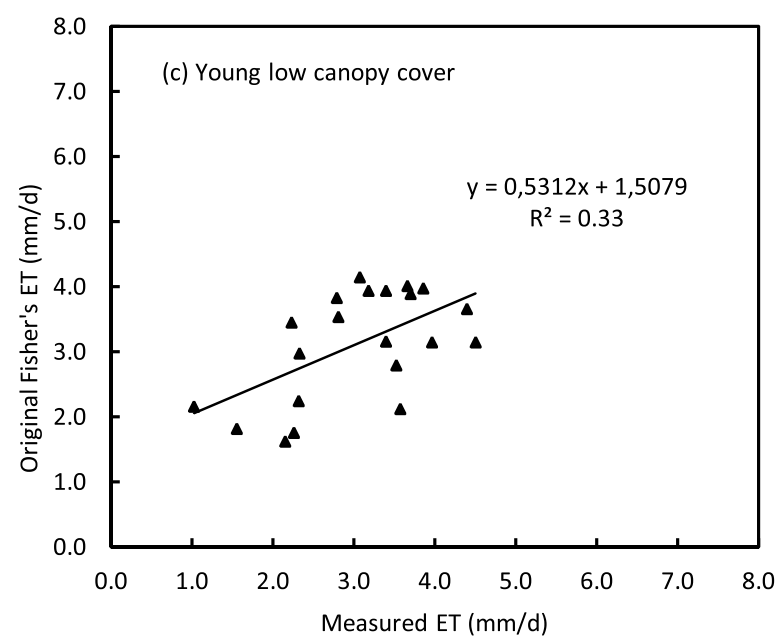

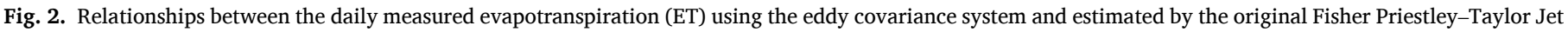
Propulsion Laboratory (PT-JPL) model in apple orchards with (a) high and (b) medium and (c) low canopy covers. 
Table 3

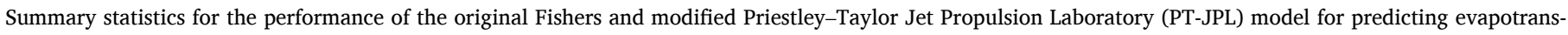
piration at sites in Koue Bokkeveld (KBV) and Elgin/Grabouw/Vyeboom/Villiersdorp (EGVV) during the 2014/15, 2015/16 and 2016/17 growing seasons.

\begin{tabular}{|c|c|c|c|c|c|c|c|c|c|c|c|c|c|}
\hline \multirow[t]{2}{*}{ Season } & \multirow[t]{2}{*}{ Region } & \multirow[t]{2}{*}{ Orchard name } & \multirow[b]{2}{*}{ Slope } & \multicolumn{4}{|c|}{ PT-JPL Original Fishers } & \multirow[b]{2}{*}{ Slope } & \multicolumn{4}{|c|}{ Modified PT-JPL } & \multirow[b]{2}{*}{$\mathrm{N}$} \\
\hline & & & & $\mathrm{R}^{2}$ & NSE & RMSE (mm/d) & $\mathrm{MAE}(\mathrm{mm} / \mathrm{d})$ & & $\mathrm{R}^{2}$ & NSE & RMSE (mm/d) & $\operatorname{MAE}(\mathrm{mm} / \mathrm{d})$ & \\
\hline \multirow[t]{4}{*}{$2014 / 15$} & KBV & FBGD & - & - & - & - & - & - & - & - & - & - & - \\
\hline & & FBCP & - & - & - & - & - & - & - & - & - & - & - \\
\hline & & NBGD & -0.12 & 0.02 & -1.80 & 3.47 & 3.40 & 0.84 & 0.54 & 0.17 & 1.48 & 1.30 & 34 \\
\hline & & NBRG & - & - & - & - & - & - & - & - & - & - & - \\
\hline \multirow[t]{4}{*}{$2015 / 16$} & EGVV & FBGD & -0.12 & 0.11 & -5.25 & 3.41 & 2.96 & 0.58 & 0.75 & 0.41 & 1.07 & 0.91 & 28 \\
\hline & & FBCP & 0.77 & 0.35 & -1.55 & 1.01 & 0.94 & 1.20 & 0.55 & 0.42 & 0.60 & 0.49 & 29 \\
\hline & & NBGR & 0.42 & 0.29 & 0.22 & 0.76 & 0.60 & 0.92 & 0.71 & 0.50 & 0.64 & 0.57 & 19 \\
\hline & & NBCR & - & - & - & - & - & - & - & - & - & - & - \\
\hline \multirow[t]{4}{*}{$2016 / 17$} & KBV & BGD & 1.34 & 0.65 & -0.31 & 0.70 & 0.59 & 1.21 & 0.67 & 0.12 & 1.09 & 1.00 & 14 \\
\hline & & ВСР & 0.28 & 0.96 & -10.93 & 3.24 & 3.17 & 0.43 & 0.67 & 0.08 & 1.99 & 1.91 & 6 \\
\hline & EGVV & BGD & - & - & - & - & - & - & - & - & - & - & - \\
\hline & & ВСР & 0.17 & 0.21 & -1.19 & 2.07 & 1.78 & 0.72 & 0.57 & 0.35 & 0.63 & 0.54 & 16 \\
\hline
\end{tabular}

FBGD $=$ Full-bearing Golden Delicious, FBCP $=$ Full bearing Cripps Pink, BGD $=$ Bearing Golden Delicious Reinders $\AA$, BCP $=$ Bearing Cripps Pink, NBGD $=$ Nonbearing Golden Delicious Reinders ${ }^{\circledR}$, NBRG $=$ Non-bearing Rosy Glow, NBCR = Non-bearing Cripps Red.
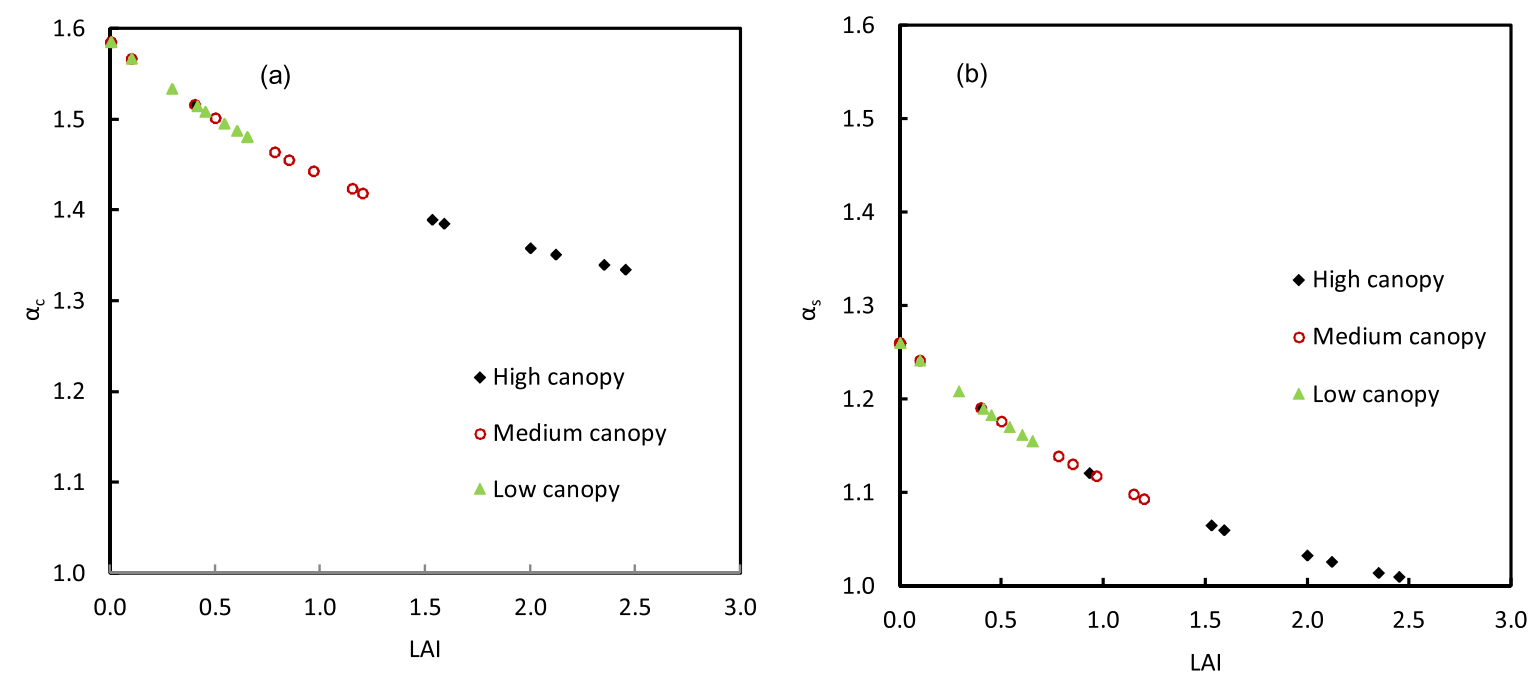

Fig. 3. Relationships between modified (a) canopy transpiration $\left(\alpha_{c}\right)$ and (b) soil evaporation $\left(\alpha_{s}\right)$ Priestley \& Taylor coefficient and leaf area index (LAI) for apple orchards with varying canopy cover.

reach full-bearing age in the semi-arid region of Western Cape on a daily time scale.

\subsection{Performance of the improved PT-JPL model}

The modified PT-JPL model predicted the daily transpiration rates for the entire season reasonably well except in May and June when the trees were reaching the senescence stage (Fig. 4). Typical examples for three orchards with high, medium and low canopy cover are shown in Fig. 4 a-c. The trends in the other orchards were similar to those shown in Fig. 4 and statistical comparisons of the model estimates against measured transpiration data are shown in Table 4. Daily transpiration in mature high canopy cover orchard was reasonably predicted by the modified PT-JPL model throughout the growing season with an $\mathrm{R}^{2}$ model of 0.78 . The root mean square error was low at $\pm 0.66 \mathrm{~mm} /$ $\mathrm{d}$ while the mean absolute error (MAE) was only $\pm 0.50 \mathrm{~mm} / \mathrm{d}$ and the Nash-Sutcliffe efficiency (NSE) was 0.65 (Table 4). Model predictions of transpiration in medium canopy cover orchards were also reasonable with overestimation and underestimation at the start and end of the growing season, respectively. The root mean square and mean absolute errors were \pm 0.46 and $\pm 0.35 \mathrm{~mm} / \mathrm{d}$, respectively (Table 4). The modelled vs measured transpiration in the young low canopy cover orchards was quite reasonable, although the scatter tended to be larger (Fig. 4c). Reasons for the low predictive ability of the model in young orchards are not clear. The $\mathrm{R}^{2}$ of modelled and measured $\mathrm{T}$ values was 0.73 , and the RMSE was $\pm 0.29 \mathrm{~mm} / \mathrm{d}$.

The modified PT-JPL model also estimated evapotranspiration quite well in all apple orchards with sufficient measured ET data (Table 3). Outputs from the model were compared against eddy covariance ET flux measured data for orchards with high, medium and low canopy cover. The results show that the modified model performed better that the original model, with the RMSE varying from $\pm 0.60 \mathrm{~mm} / \mathrm{d}$ to $\pm 1.99 \mathrm{~mm} /$ $\mathrm{d}$, the MAE varied from $\pm 0.49 \mathrm{~mm} / \mathrm{d}$ to $\pm 1.91 \mathrm{~mm} / \mathrm{d}$, and $\mathrm{R}^{2}$ varied from 0.54 to 0.75 . Overall, the modified PT-JPL model performed better with lower RMSE and MAE and higher NSE (Table 3).

Therefore, this study highlights that, for irrigated crops that are sensitive to soil water deficit and to the atmospheric vapour pressure deficit, constraint factors for these stressors should be included for optimal model performance. Besides the present study, Purdy et al. (2018) also investigated the incorporation of soil moisture to constrain soil evaporation and canopy transpiration in the PT-JPL model but in a natural ecosystem. In that study, they used soil moisture data derived from Soil Moisture Active Passive Mission (SMAP) to model ET. The modified model showed reduced errors and increased explanation of 

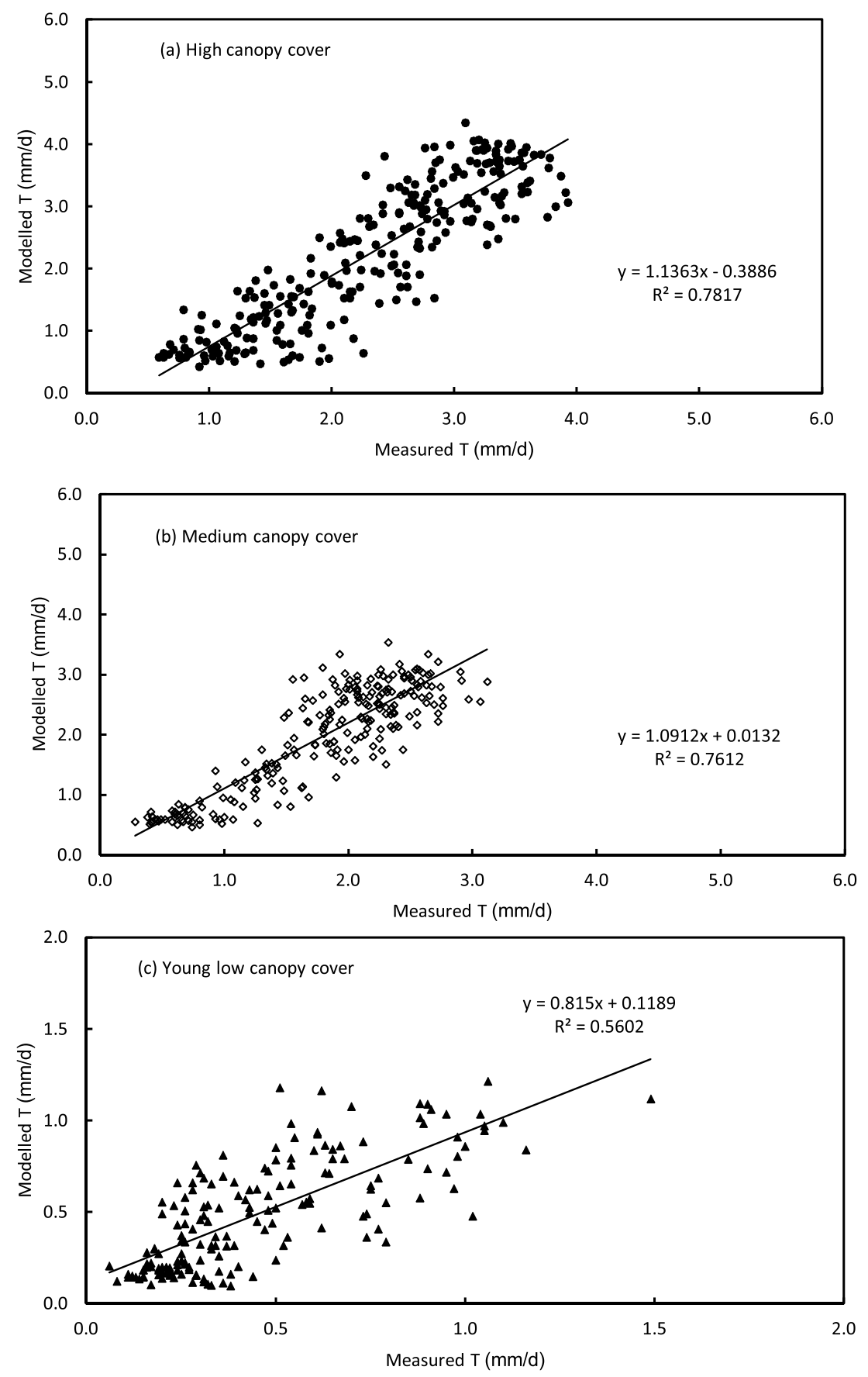

Fig. 4. Comparisons between the measured and modelled daily transpiration (T) over the entire growing season in (a) high, (b) medium and (c) low canopy cover apple orchards.

variance with the greatest improvements in water limited natural ecosystems.

The seasonal dynamics of ET and its components in high, medium and low canopy cover orchards are shown in Fig. 5 a-c. The modelled daily ET and its components showed that orchard floor evaporation dominated ET at the beginning of the season in all orchards. However, the rapid increase in leaf area after bud break resulted in transpiration being almost double the orchard floor evaporation in November and this trend persisted throughout the season for mature high canopy orchards (Fig. 5a). Transpiration contributed $75 \%$ to ET in mature orchards. In young low canopy cover orchards, however, orchard floor evaporation was higher than tree transpiration throughout the growing season (Fig. 5c). The high evaporation from the orchard floor was a result of the relatively small canopy cover (peak LAI $\sim 1.0$ ) even in the summer season when the canopy size was at its maximum. The evaporation from the canopy and orchards floor accounted for $22 \%$ and $78 \%$, respectively, of the total ET (Fig. 5c). Lastly, in the medium canopy cover orchards the contribution of the orchard floor evaporation and transpiration to ET were almost equal throughout the growing season (Fig. 5b). In terms of the percentage of each component, transpiration contributed $59 \%$ of the ET whilst, $41 \%$ came from the soil evaporation.

\section{Conclusions}

An accurate estimate of ET is essential especially in semi-arid regions where there is less water being competed for by different users. Different 
Table 4

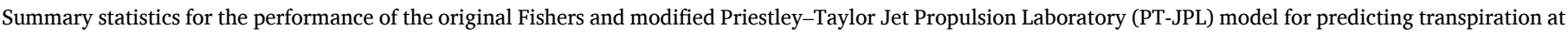
sites in Koue Bokkeveld (KBV) and Elgin/Grabouw/Vyeboom/Villiersdorp (EGVV) during the 2014/15, 2015/16 and 2016/17 growing seasons.

\begin{tabular}{|c|c|c|c|c|c|c|c|c|c|c|c|c|c|}
\hline \multirow[t]{2}{*}{ Season } & \multirow[t]{2}{*}{ Region } & \multirow[t]{2}{*}{ Orchard name } & \multirow[b]{2}{*}{ Slope } & \multicolumn{4}{|c|}{ PT-JPL Original Fishers } & \multirow[b]{2}{*}{ Slope } & \multicolumn{5}{|c|}{ Modified PT-JPL } \\
\hline & & & & $\mathrm{R}^{2}$ & NSE & RMSE (mm/d) & $\mathrm{MAE}(\mathrm{mm} / \mathrm{d})$ & & $\mathrm{R}^{2}$ & NSE & RMSE (mm/d) & MAE (mm/d) & $\mathrm{N}$ \\
\hline \multirow[t]{4}{*}{$2014 / 15$} & \multirow[t]{4}{*}{ KBV } & FBGD & 1.26 & 0.70 & 0.38 & 0.63 & 0.52 & 1.01 & 0.84 & 0.54 & 0.73 & 0.62 & 189 \\
\hline & & FBCP & 1.42 & 0.35 & -0.35 & 0.74 & 0.58 & 1.10 & 0.66 & 0.42 & 0.50 & 0.40 & 120 \\
\hline & & NBGD & 1.73 & 0.55 & -4.63 & 0.84 & 0.69 & 0.98 & 0.64 & 0.51 & 0.25 & 0.19 & 191 \\
\hline & & NBRG & 0.84 & 0.43 & 0.39 & 0.34 & 0.26 & 0.94 & 0.65 & 0.41 & 0.28 & 0.22 & 141 \\
\hline \multirow{4}{*}{$2015 / 16$} & \multirow[t]{4}{*}{ EGVV } & FBGD & 1.00 & 0.74 & 0.50 & 0.80 & 0.63 & 0.91 & 0.81 & 0.65 & 0.66 & 0.50 & 274 \\
\hline & & FBCP & 1.14 & 0.78 & 0.50 & 0.63 & 0.54 & 1.13 & 0.81 & 0.61 & 0.55 & 0.44 & 266 \\
\hline & & NBGR & 1.33 & 0.57 & -0.84 & 0.47 & 0.38 & 0.89 & 0.73 & 0.35 & 0.29 & 0.23 & 197 \\
\hline & & NBCR & 2.07 & 0.20 & -5.19 & 0.59 & 0.45 & 0.39 & 0.71 & 0.16 & 0.32 & 0.26 & 258 \\
\hline \multirow[t]{4}{*}{$2016 / 17$} & \multirow[t]{2}{*}{ KBV } & BGD & 0.85 & 0.56 & 0.34 & 0.52 & 0.43 & 1.05 & 0.62 & 0.27 & 0.55 & 0.45 & 264 \\
\hline & & ВСР & 0.72 & 0.33 & -1.42 & 0.82 & 0.70 & 1.09 & 0.63 & 0.20 & 0.42 & 0.35 & 127 \\
\hline & \multirow[t]{2}{*}{ EGVV } & BGD & 1.98 & 0.62 & -4.01 & 0.69 & 0.53 & 0.80 & 0.73 & 0.63 & 0.29 & 0.24 & 134 \\
\hline & & ВСР & 1.12 & 0.76 & 0.66 & 0.39 & 0.30 & 1.09 & 0.80 & 0.55 & 0.46 & 0.35 & 251 \\
\hline
\end{tabular}

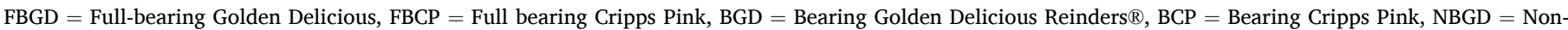
bearing Golden Delicious Reinders ${ }^{\circledR}, \mathrm{NBRG}=$ Non-bearing Rosy Glow, NBCR $=$ Non-bearing Cripps Red.

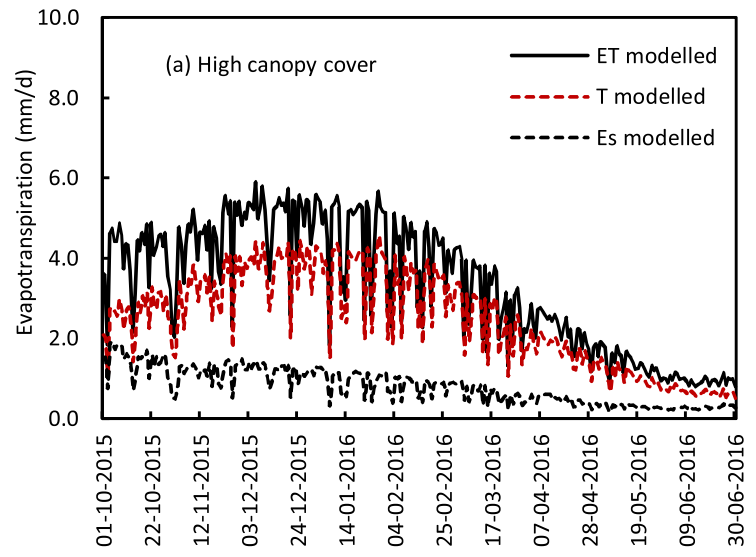

Date

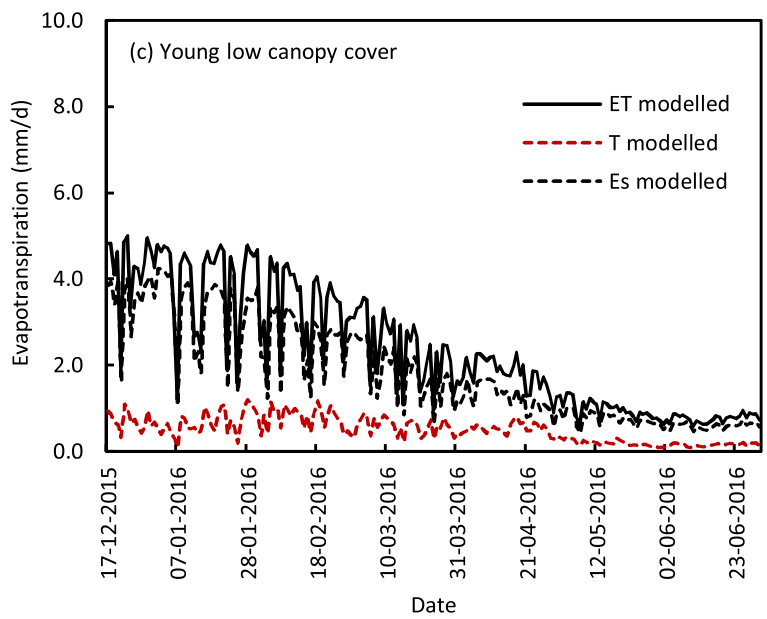

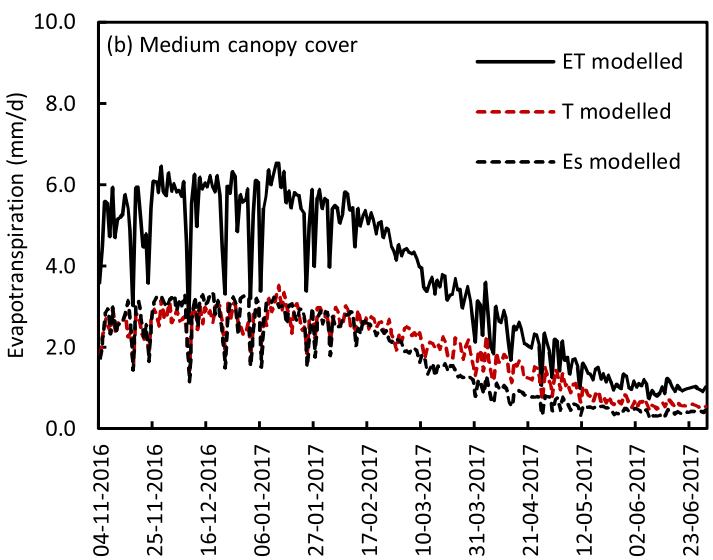

Date

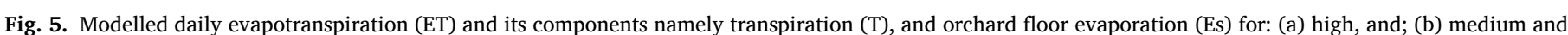
(c) low canopy cover compared with the measured ET from the eddy covariance system.

ET models of varying complexities and data input requirements are available, and their applicability in different climatic regions and scales is consistently under scrutiny. In this study, we adopted, modified and applied PT-JPL evapotranspiration model in orchards with varying canopy cover. Our findings showed that the modified PT-JPL model performance was satisfactory in most instances although further validation of the model with data from a range of sites is required to build confidence in the model. Model simulations of the transpiration component were most reliable, but uncertainties are higher with the orchard ET estimates given the difficulties to accurately model the 
orchard floor evaporation fluxes.

\section{CRediT authorship contribution statement}

Nompumelelo Thelma Mobe: Conceptualization, Methodology, Investigation, Formal analysis, Writing - original draft. Sebinasi Dzikiti: Investigation, Writing - review \& editing, Supervision. Timothy Dube: Writing - review \& editing. Dominic Mazvimavi: Writing - review \& editing. Zanele Ntshidi: Investigation, Writing - review \& editing.

\section{Declaration of Competing Interest}

The authors report no declarations of interest.

\section{Acknowledgement}

This project was initiated, supported and managed by the Water Research Commission (project no WRC K5 2398/4) and the South African Apple and Pear Producers' Association (SAAPPA). We are sincerely grateful for the financial support from these entities. Additional South African Parliamentary Grant funding through the Council for Scientific and Industrial Research (project number P1AHS01) and the National Research Foundation (NRF-DST) -Professional Development Programme is also gratefully acknowledged. Authors are also grateful to Du Toit Agri Group, Radyn, Southfield, Vyeboom and Dennebos farms who allowed us to use their productive orchards for our experiments. Lastly we thank Dr Theresa Volschenk and Prof SJE Midgley for assistance with data collection at various stages of the project.

\section{References}

Agam, N., Kustas, W.P., Anderson, M.C., Norman, J.M., Colaizzi, P.D., Howell, T.A., Prueger, J.H., Meyers, T.P., Wilson, T.B., 2010. Application of the priestley-taylor approach in a two-source surface energy balance model. J. Hydrometeorol. 11, 185-198. https://doi.org/10.1175/2009JHM1124.1.

Ai, Z., Yang, Y., 2016. Modification and validation of Priestley-Taylor model for estimating cotton evapotranspiration under plastic mulch condition.

J. Hydrometeorol. 17, 1281-1293. https://doi.org/10.1175/JHM-D-15-0151.1.

Allen, R.G., Luis, S.P., RAES, D., Smith, M., 1998. FAO Irrigation and Drainage Paper No. 56. Crop Evapotranspiration (guidelines for computing crop water requirements). Irrig. Drain 300, 300. https://doi.org/10.1016/j.eja.2010.12.001.

Annandale, J.G., Jovanovic, N.Z., Campbell, G.S., Du Sautoy, N., Benadé, N., 2003. A two-dimensional water balance model for micro-irrigated hedgerow tree crops. Irrig. Sci. 22, 157-170. https://doi.org/10.1007/s00271-003-0081-7.

Aragon, B., Houborg, R., Tu, K., Fisher, J.B., McCabe, M., 2018. Cubesats enable high spatiotemporal retrievals of crop-water use for precision agriculture. Remote Sens. (Basel) 10, 1-22. https://doi.org/10.3390/rs10121867.

Burgess, S.S.O., Adams, M.A., Turner, N.C., Beverly, C.R., Ong, C.K., Khan, A.A.H. Bleby, T.M., 2001. An improved heat pulse method to measure low and reverse rates of sap flow in woody plants. Tree Physiol. 21, 589-598. https://doi.org/10.1093/ treephys/21.9.589.

Ding, R., Kang, S., Li, F., Zhang, Y., Tong, L., 2013. Evapotranspiration measurement and estimation using modified Priestley-Taylor model in an irrigated maize field with mulching. Agric. For. Meteorol. 168, 140-148. https://doi.org/10.1016/j. agrformet.2012.08.003.

Dragoni, D., Lakso, A.N., 2011. An apple-specific ET model. Acta Hortic. 903, 1175-1180. https://doi.org/10.17660/ActaHortic.2011.903.164.

Dzikiti, S., Gush, M.B., Taylor, N.J., Volschenk, T., Midgley, S., Lötze, E., Schmeisser, M., Doko, Q., 2017. Measurement and modelling of water use by high yielding apple orchards and orchards of different age groups in the winter rainfall areas of South Africa. Acta Hortic. 1150, 31-38. https://doi.org/10.17660/ ActaHortic. 2017.1150.5.

Dzikiti, S., Volschenk, T., Midgley, S.J.E., Lötze, E., Taylor, N.J., Gush, M.B., Ntshidi, Z. Zirebwa, S.F., Doko, Q., Schmeisser, M., Jarmain, C., Steyn, W.J., Pienaar, H.H., 2018a. Estimating the water requirements of high yielding and young apple orchards in the winter rainfall areas of South Africa using a dual source evapotranspiration model. Agric. Water Manag. 208, 152-162. https://doi.org/10.1016/j. agwat.2018.06.017.

Dzikiti, S., Volschenk, T., Midgley, S., Gush, M., Taylor, N., Lotze, E., Zirebwa, S., Ntshidi, Z., Mobe, N., Schmeisser, M., Doko, Q., 2018b. Quantifying water use and water productivity of high performing apple orchards of different canopy report to the, water research commission.

Dzikiti, S., Jovanovic, N.Z., Bugan, R.D., Ramoelo, A., Majozi, N.P., Nickless, A., Cho, M. A., Le Maitre, D.C., Ntshidi, Z., Pienaar, H.H., 2019. Comparison of two remote sensing models for estimating evapotranspiration: algorithm evaluation and application in seasonally arid ecosystems in South Africa. J. Arid Land 11, 495-512. https://doi.org/10.1007/s40333-019-0098-2.

Elfarkh, J., Ezzahar, J., Er-Raki, S., Simonneaux, V., Ait Hssaine, B., Rachidi, S., Brut, A., Rivalland, V., Khabba, S., Chehbouni, A., Jarlan, L., 2020. Multi-scale evaluation of the TSEB model over a complex agricultural landscape in Morocco. Remote Sens. (Basel) 12, 1181. https://doi.org/10.3390/rs12071181.

Ershadi, A., McCabe, M.F., Evans, J.P., Chaney, N.W., Wood, E.F., 2014. Multi-site evaluation of terrestrial evaporation models using FLUXNET data. Agric. For. Meteorol. 187, 46-61. https://doi.org/10.1016/j.agrformet.2013.11.008.

Fernández, J., 2017. Plant-based methods for irrigation scheduling of woody crops. Horticulturae 3, 35. https://doi.org/10.3390/horticulturae3020035.

Fisher, J.B., Tu, K.P., Baldocchi, D.D., 2008. Global estimates of the land-atmosphere water flux based on monthly AVHRR and ISLSCP-II data, validated at 16 FLUXNET sites. Remote Sens. Environ. 112, 901-919. https://doi.org/10.1016/j. rse.2007.06.025.

García, M., Sandholt, I., Ceccato, P., Ridler, M., Mougin, E., Kergoat, L., Morillas, L. Timouk, F., Fensholt, R., Domingo, F., 2013. Actual evapotranspiration in drylands derived from in-situ and satellite data: assessing biophysical constraints. Remote Sens. Environ. 131, 103-118. https://doi.org/10.1016/j.rse.2012.12.016.

Gomis-Cebolla, J., Jimenez, J.C., Sobrino, J.A., Corbari, C., Mancini, M., 2019. Intercomparison of remote-sensing based evapotranspiration algorithms over amazonian forests. Int. J. Appl. Earth Obs. Geoinf. 80, 280-294. https://doi.org/ 10.1016/j.jag.2019.04.009.

Gong, D., Kang, S., Yao, 1., Zhang, L., 2007. Estimation of evapotranspiration and itscomponents from an apple orchard in the northwest China using sap flow and water balance. Ecohydrology 21, 931-938.

Granier, A., 1987. Evaluation of transpiration in a Douglas-fir stand by means of sap flow measurements. Tree Physiol. 3, 309-320.

Gush, M., Dzikiti, S., van der Laan, M., Steyn, M., Manamathela, S., Pienaar, H., 2019. Field quantification of the water footprint of an apple orchard, and extrapolation to watershed scale within a winter rainfall Mediterranean climate zone. Agric. For. Meteorol 271, 135-147. https://doi.org/10.1016/j.agrformet.2019.02.042.

Koech, R., Langat, P., 2018. Improving irrigation water use efficiency: a review of advances, challenges and opportunities in the Australian context. Water (Switzerland) 10. https://doi.org/10.3390/w10121771.

Kool, D., Agam, N., Lazarovitch, N., Heitman, J.L., Sauer, T.J., Ben-gal, A., 2014. 2014Kool-Et-Al-AFM-Et Partitioning Review, 184, pp. 56-70.

Lei, H.M., Yang, D.W., 2010. Interannual and seasonal variability in evapotranspiration and energy partitioning over an irrigated cropland in the North China Plain. Agric. For. Meteor. 150, 581-589. https://doi.org/10.1016/j.agrformet.2010.01.022.

Li, X., Yang, P., Ren, S., Li, Y., Liu, H., Du, J., Li, P., Wang, C., Ren, L., 2010. Modeling cherry orchard evapotranspiration based on an improved dual-source model. Agric. Water Manag. 98, 12-18. https://doi.org/10.1016/j.agwat.2010.07.019.

Liou, Y.A., Kar, S.K., 2014. Evapotranspiration estimation with remote sensing and various surface energy balance algorithms-a review. Energies 7, 2821-2849. https:// doi.org/10.3390/en7052821.

Lo Bianco, R., 2019. Water-related variables for predicting yield of apple under deficit irrigation. Horticulturae 8. https://doi.org/10.3390/horticulturae5010008.

Midgley, S.J.E., Lotze, E., 2011. Climate change in the Western Cape of South Africa: trends, projections and implications for chill unit accumulation. Acta Hortic. 903, 1127-1134. https://doi.org/10.17660/ActaHortic.2011.903.157.

Mobe, N.T., Dzikiti, S., Zirebwa, S.F., Midgley, S.J.E., von Loeper, W., Mazvimavi, D., Ntshidi, Z., Jovanovic, N.Z., 2020a. Estimating crop coefficients for apple orchards with varying canopy cover using measured data from twelve orchards in the Western Cape Province, South Africa. Agric. Water Manag. 233. https://doi.org/10.1016/j. agwat.2020.106103.

Mobe, N.T., Dzikiti, S., Volschenk, T., Zirebwa, S.F., Ntshidi, Z., Midgley, S.J.E., Steyn, W.J., Lötze, E., Mpandeli, S., 2020b. Using sap flow data to assess variations in water use and water status of apple orchards of varying age groups in the Western Cape Province of South Africa. Water SA 46, 1-13.

Moyano, M.C., Garcia, M., Palacios-Orueta, A., Tornos, L., Fisher, J.B., Fernández, N., Recuero, L., Juana, L., 2018. Vegetation water use based on a thermal and optical remote sensing model in the mediterranean region of Doñana. Remote Sens. (Basel) 10. https://doi.org/10.3390/rs10071105.

Mpelasoka, B.S., Green, S., Behboudian, M.H., 2001. Water use, yield and fruit quality of lysimeter-grown apple trees: responses to deficit irrigation and to crop load. Irrig. Sci. 20 (3), 107-113. https://doi.org/10.1007/s002710100041.

Odi-Lara, M., Campos, I., Neale, C.M.U., Ortega-Farías, S., Poblete-Echeverría, C., Balbontín, C., Calera, A., 2016. Estimating evapotranspiration of an apple orchard using a remote sensing-based soil water balance. Remote Sens. (Basel) 8. https://doi. org/10.3390/rs8030253.

Ortega-Farias, S., Lopéz-Olivari, R., Poblete-Echeverría, C., Zuñiga, M., 2012. Evaluation of a two-layer model and sap flow to estimate olive transpiration. Acta Hortic. 951, 147-152. https://doi.org/10.17660/ActaHortic.2012.951.17.

Ouyang, Z.P., Mei, X.R., Li, Y.Z., Guo, J.X., et al., 2013. Measurements of water dissipation and water use efficiency at the canopy level in a peach orchard. Agric. Water Manag 129, 80-86. https://doi.org/10.1016/j.agwat.2013.07.016.

Pereira, A.R., 2004. The Priestley-Taylor parameter and the decoupling factor for estimating reference evapotranspiration. Agric. For. Meteorol. 125, 305-313. https://doi.org/10.1016/j.agrformet.2004.04.002.

Pereira, A.R., Green, S.R., Nova, N.A.V., 2007. Sap flow, leaf area, net radiation and the Priestley-Taylor formula for irrigated orchards and isolated trees. Agric. Water Manag. 92, 48-52. https://doi.org/10.1016/j.agwat.2007.01.012.

Priestley, C.H.B., Taylor, R.J., 1972. On the assessment of surface heat flux and evaporation using large-scale parameters. Mon. Weather Rev. 100, 81-92. https:// doi.org/10.1175/1520-0493(1972)100<0081:otaosh >2.3.co;2. 
Purdy, A.J., Fisher, J.B., Goulden, M.L., Colliander, A., Halverson, G., Tu, K., Famiglietti, J.S., 2018. SMAP soil moisture improves global evapotranspiration. Remote Sens. Environ. 219, 1-14. https://doi.org/10.1016/j.rse.2018.09.023.

Qiu, R., Liu, C., Cui, N., Wu, Y., Wang, Z., Li, G., 2019. Evapotranspiration estimation using a modified Priestley-Taylor model in a rice-wheat rotation system. Agric. Water Manag. 224, 105755 https://doi.org/10.1016/j.agwat.2019.105755.

Rana, G., Katerji, N., De Lorenzi, F., 2005. Measurement and modelling of evapotranspiration of irrigated citrus orchard under Mediterranean conditions. Agric. For. Meteorol. 128, 199-209. https://doi.org/10.1016/j. agrformet.2004.11.001.

Shao, R., Zhang, B., Su, T., Long, B., Cheng, L., Xue, Y., Yang, W., 2019. Estimating the increase in regional evaporative water consumption as a result of vegetation restoration over the Loess Plateau. China. J. Geophys. Res. Atmos. 124, 11783-11802. https://doi.org/10.1029/2019JD031295.

Tanner, C., Jury, W., 1976. Estimating evaporation and transpiration from a row cop during incomplete cover. Agron. J. 68, 239-243. https://doi.org/10.2134/ agronj1976.00021962006800020007x.

Utset, A., Farre, I., Martinez-Cob, A., Cavero, J., 2004. Comparing Penman-Monteith and Priestley-Taylor approaches as reference evapotranspiration inputs for modeling maize water-use under Mediterranean conditions. Agric. Water Manag. 66, 205-219. https://doi.org/10.1016/j.agwat.2003.12.003.
Volschenk, T., 2017. Evapotranspiration and crop coefficients of Golden Delicious/M793 apple trees in the Koue Bokkeveld. Agric. Water Manag. 194, 184-191. https://doi. org/10.1016/j.agwat.2017.09.002.

Volschenk, T., de Villiers, J., Beukes, O., 2003. The Selection and Calibration of a Model for Irrigation Scheduling of Deciduous Fruit Orchards.

Wang, D., Wang, L., 2017. Dynamics of evapotranspiration partitioning for apple trees of different ages in a semiarid region of northwest China. Agric. Water Manag. 191, 1-15. https://doi.org/10.1016/j.agwat.2017.05.010.

Yang, Z., Zhang, Q., Hao, X., Yue, P., 2019. Changes in evapotranspiration over global semiarid regions 1984-2013. J. Geophys. Res. Atmos. 124, 2946-2963. https://doi. org/10.1029/2018JD029533.

Yao, Y., Liang, S., Cheng, J., Liu, S., Fisher, J.B., Zhang, X., Jia, K., Zhao, X., Qin, Q., Zhao, B., Han, S., Zhou, Guangsheng, Zhou, Guoyi, Li, Y., Zhao, S., 2013. MODISdriven estimation of terrestrial latent heat flux in China based on a modified Priestley-Taylor algorithm. Agric. For. Meteorol. 171-172, 187-202. https://doi. org/10.1016/j.agrformet.2012.11.016.

Zanotelli, D., Montagnani, L., Andreotti, C., Tagliavini, M., 2019. Evapotranspiration and crop coefficient patterns of an apple orchard in a sub-humid environment. Agric. Water Manag. 226, 105756 https://doi.org/10.1016/j.agwat.2019.105756.

Zhang, K., Ma, J., Zhu, G., Ma, T., Han, T., Feng, L.L., 2017. Parameter sensitivity analysis and optimization for a satellite-based evapotranspiration model across multiple sites using moderate resolution imaging spectroradiometer and flux data J. Geophys. Res. 122, 230-245. https://doi.org/10.1002/2016JD025768. 